\title{
MODIFYING NOUNS: AN ENGLISH-SPANISH CORPUS-BASED CONTRAST OF THREE WORD PAIRS
}

\author{
NoElia RAMÓN GARCía \\ University of León
}

\begin{abstract}
The modification of nouns is a problematic area in contrasting English and Spanish. The different typologies to which these two languages belong determine essential differences, such as the unmarked position of adjectives, before nouns in English and after nouns in Spanish. The aim of this study is to set up a list of the most common characterizing resources for nouns in both languages, and establish their different distribution, so that trends in usage can be detected. A number of concordances of three word pairs have been selected from two large monolingual corpora, Cobuild and CREA (Corpus de Referencia del Español Actual). The data have been analysed to describe the type of modifiers that occur in both languages. This contrastive analysis provides useful data in areas such as translation, foreign language learning and teaching, or descriptive linguistics. The translation process between English and Spanish is the main focus of this paper.
\end{abstract}

\section{INTRODUCTION}

One of the obvious differences in grammatical patterns that exist between English and Spanish is the qualitative modification of nouns, which we will also refer to as characterization in this paper. These differences make of this issue one of the main problems when translating texts of any type from English into Spanish. The typological differences existing between Germanic and Romance languages are clearly observable in this particular grammatical area. The most obvious example is the different unmarked position of the most basic and universal noun modifiers, i.e. adjectives, in these two languages: premodification 
by adjectives in English and postmodification in Spanish. Furthermore, related to the different language typologies is the fact that native speakers of different languages refer to the real world using culture-bound strategies that may vary greatly across languages.

In this paper we will examine noun phrases (NP) in English and Spanish. We will analyse a series of NPs in order to establish the different types of modifying structures that appear surrounding nouns in order to determine which of these constructions are the most frequent in each language. We aim at providing information about the linguistic habits of the two language communities that might help establish recommended translation patterns in Spanish for the different grammatical resources found in English.

One of the main objectives of linguistic theories has always been to explain the relationship between semantics and syntax. In other words, there is a need to understand the step that takes us from meaning to form by means of a particular set of syntactic structures. Different authors have dealt with this topic in the second half of the $20^{\text {th }}$ century, among them Tesnière (1959), Sommerfeldt \& Starke (1984), Bondarko (1991), Pottier (1992) and Jürgens (1999). All these theories refer to the existence of a multiplicity of syntactic structures available for expressing one and the same meaning "In diesem Sinne verstehe ich Syntax als Organisationsweise von Semantik. Dabei muß betont werden, daß es in der Regel verschiedene syntaktische Strukturen zur Organisation einer semantischen Struktur gibt." (Jürgens 1999: 15). This idea is not only applicable to the mechanisms at work within one particular language, but also to aspects related to translation, since it accounts for the possibility of two different grammatical realisations in two languages conveying the same meaning.

Our study is based on the proposal made by Bondarko (1991) for explaining the interaction between meaning and grammar. This author defines a notion of functional-semantic fields similar to the polysystem theory in descriptive translation studies (Toury 1995). One particular syntactic structure that is considered to be the most central one is attributed to each of these fields. Other syntactic constructions may also be able to convey the same meaning, but they are less common than the first one and thus more peripheral, less central. "Underlying each functionalsemantic field is a particular semantic category constituting the semantic invariant which unites heterogeneous language means and conditions their interaction." (Bondarko 1991: 22).

This paper deals with the expression of quality in English and Spanish nouns. We set out to establish the functional-semantic fields of nominal modification in these two languages, designing a framework that clearly distinguishes the most 
central syntactic structures in both languages. The subsequent contrast between the two different functional-semantic fields should yield useful information about the different trends in these languages when it comes to modifying nouns and also about the options available when translating from English into Spanish.

With this aim in mind we have decided to use computerised language corpora as working tools. Corpus linguistics has become an essential factor in contrastive studies over the past few years. The enormous amounts of real texts produced by native speakers provide very useful information concerning language in use. The authenticity of these texts validates the results found in the analysis of any linguistic aspect, especially in the case of contrastive studies with a translational approach, where real language use is essential in order to determine the linguistic habits of the target language community. The corpora selected for this paper are the Cobuild Direct and the CREA (Corpus de Referencia del Español Actual). Within these two monolingual corpora, the texts that have been employed are those published in the written media (newspapers and magazines) and written in the European varieties of our two working languages.

Our primary working hypothesis considers that there are substantial differences between English and Spanish in what refers to the qualitative modification of nouns, since this aspect is particularly difficult to deal with when translating from one language into the other. There may be more or less similar resources such as adjectives or relative clauses that carry out this particular meaning in both languages, but the distribution and the frequency of use may not be the same. The well-known trend of the English language to prefer premodification, while the Spanish language tends towards postmodification should also be validated in this study.

\section{CHARACTERIZATION: DEFINITION AND DIFFERENCES BETWEEN ENGLISH AND SPANISH}

Since 1958 in Vinay \& Darbelnet's Stylistique comparée du français et de l'anglais the term characterization has been used to refer to the different grammatical resources that may be used in a particular language to add qualitative information to the content of nouns and verbs. "La caractérisation est l'ensemble des moyens par lesquels la langue décrit les gens, les choses et les idées d'une part, et les actions d'autre part." (Darbelnet 1969: 41). In this paper, we deal only with the characterization of nouns, and only with characterization in the attributive position. This is due to the fact that adjectives -the most obvious characterizing resource for nouns- have been shown to occur three times more often in attributive position than in predicative position (Biber et al. 1999: 506). 
Furthermore, the most important differences between English and Spanish lie in attributive modification.

There is no doubt that the internal typological structure of any language will condition all the syntactic aspects related to the expression of a particular meaning. The way a language community perceives the real world and its environment is directly linked to the way the native speakers of that community use language to refer to the real world. This well-known fact is particularly important in characterization. English and Spanish are two genetically related languages that belong to different branches of the Indo-European language family, the Germanic branch and the Romance branch, respectively. This typological fact determines to a great extent a number of issues related to syntax and word order, two crucial factors in the expression of quality in nouns. English is considered to have a structure that is particularly suitable for a graphic description of reality, full of physical details. In contrast, Spanish has traditionally been described as being a language that remains on the level of abstraction, far from any concern for the concrete and objective facts (Vázquez Ayora 1977: 44). This difference is reflected in the lexical dimension of the use of adjectives, and thus in any other modifying structure. The high degree of nominalization present in the English language has an influence on characterization too, since it allows for nouns to be freely used as adjectives. In contrast, Spanish presents a much lower level of nominalization.

There is yet another formal aspect where the different ways of characterizing nouns in English and Spanish are clearly visible, and this is word order. The unmarked position for an adjective in English is before the noun it modifies, while postmodification is the unmarked position in Spanish. Both languages allow for reverse positions, but the semantic nuances change and make these alternative positions clearly marked. In consequence, other possible characterizing resources in these languages will adopt the corresponding unmarked position too, if this is syntactically possible. For example, when nouns are used to modify other nouns, these units with adjectival use appear preceding the modified noun in English (guest bouse, lemon cake), and after the modified noun in Spanish (bombre orquesta, coche bomba).

The different ways of describing the real world, the flexibility of the English language to use nouns as adjectives and the opposite unmarked position of adjectives suggest the existence of important differences in the way the expression of quality is organised in these two languages.

Characterization is a very wide semantic field. There are a number of different linguistic resources to carry out the semantic function of nominal modification. Adjectives are the clearest example of grammatical units with this meaning, but they 
are by no means the only formal resources that may be used with this purpose. Other word classes can be used in similar ways, "especially nouns, adverbs, and semi-determiners, so that the boundaries of the adjective category are not easy to draw." (Biber et al. 1999: 506).

In attributive position some of the most frequent characterizing resources in English and Spanish are adjectives and adjective phrases (henceforth Adj.P), prepositional phrases (henceforth PP), relative clauses, NPs, non-finite clauses, etc.

The foundation of this paper is a semantic one, since we are dealing with our topic from an onomasiological point of view, i.e. from meaning to form, from the semantics of characterization to the grammatical forms that express it. We will focus here on the different frequency of occurrence and distribution of these constructions on the part of native speakers of English and Spanish.

\section{WORKING PROCEDURE}

This is a corpus-based study and the two corpora used to obtain the data necessary for the analysis are the Cobuild Direct, the smaller on-line version of the Cobuild/Bank of English corpus, and Spanish corpus CREA. Both corpora contain millions of words, so smaller samples were carefully selected within each one to make our sample corpora comparable. Only written texts were selected, only texts published in the media, and only texts produced in the European varieties of English and Spanish. With these limitations we obtained two subcorpora of approximately 22 million words in each language, thus making the two corpora comparable in size too.

In order to analyse the type of characterization that modifies nouns in English and Spanish, we have chosen a number of three sample nouns with their referential equivalents in the other language, so that we could use these as input for the corpus search. The selected units were man-bombre, house-casa, and time-tiempo. These three noun pairs represent groups of human nouns, inanimate concrete nouns, and abstract nouns, respectively, and they have been selected because of their high frequency of occurrence in both languages. 500 concordances have been extracted for each example, and all instances have been analysed in order to determine what type of modifying construction appeared next to the node nouns. The results of the descriptive analysis have then been juxtaposed and contrasted. The final aim was to draw conclusions from the data provided that might be useful when translating from English into Spanish. 


\section{CONTRASTIVE ANALYSIS}

\subsection{HUMAN NOUNS}

The analysis of 500 concordances of the nouns man and hombre revealed data about the amount of examples that presented qualitative modification in both cases. The percentage of characterized examples is very similar in both languages, approximately $65 \%$ of the cases. In the remaining cases these nouns appear alone, or preceded by articles, determiners, numerals, or other non-qualitative modifiers. This indicates that there seems to be a clear trend in speakers of both languages to make qualitative comments when talking about human nouns.

The central part of our contrast focuses on the comparison of the characterizing resources found modifying the selected nouns. Only the resources that present the highest number of occurrences are shown here. Table 1 includes the six most frequent structures found in our corpus samples, which amount to around $70 \%$ of the total.

\begin{tabular}{|lr|lr|}
\hline \multicolumn{2}{|c|}{ ENGLISH } & \multicolumn{2}{c|}{ SPANISH } \\
\hline man + Relative clause & $20.78 \%$ & bombre + Relative clause & $21.95 \%$ \\
\hline Adjective + man & $20.48 \%$ & bombre + de-phrase & $15.85 \%$ \\
\hline Noun + man & $13.25 \%$ & bombre + adjective & $15.54 \%$ \\
\hline man + Adj.P / participle clause & $6.09 \%$ & bombre + Adj.P / participle clause & $8.53 \%$ \\
\hline man + of-phrase & $5.72 \%$ & bombre + Adj.P + relative clause & $3.65 \%$ \\
\hline 2 adjectives + man & $4.21 \%$ & hombre + Adj.P + de-phrase & $3.35 \%$ \\
\hline TOTAL & $\mathbf{7 0 . 5 3 \%}$ & TOTAL & $\mathbf{6 8 . 8 7 \%}$ \\
\hline
\end{tabular}

Table 1. Characterizing resources for man and hombre.

Postmodification is the only option in Spanish, whereas three out of six resources in English are premodifying. Relative clauses present a very high percentage of occurrences in both languages, approximately 20\%: the man who led the protest, the man I love, etc. However, relative clauses are clearly the most central resource in Spanish (un hombre que consiguió buir de la justicia, un hombre que reclamaba su ayuda, etc.), while in English the premodifying adjective reaches almost the same frequency of use. There is a stronger trend towards the use of adjectives as modifiers among native speakers of English than 
among native speakers of Spanish, always in terms of their respective unmarked position: a young man, un hombre idóneo, etc.

In Spanish the PP where the head preposition is de, also called de-phrase in this paper, has a frequency of occurrence of $15.85 \%$. It is even more common than the adjective as a characterizing form in this language, revealing itself as one of the most common and straightforward options for Spanish speakers: un bombre de moda, un hombre de suerte, el hombre de confianza, etc. The formal equivalents in English, of-phrases, occur in only $5.72 \%$ of the cases: man of the year, man of the left, etc. In contrast, the use of a noun as a premodifying structure with adjectival function has a frequency of $13.25 \%$ in English, similar to the Spanish de-phrase and the single adjective: museum man, key man, soccer man, etc. This confirms the hypothesis usually developed by native speakers of Spanish learning English that often noun plus noun compounds in English correspond to structures with de-phrases in Spanish. The different preferences of the two language communities are clearly illustrated in this case: while the English language shows a trend towards nominal composition, Spanish uses de-phrase as a productive and effective formula for modifying nouns.

The formal equivalent of the English noun plus noun structure (13.25\%) does exist in Spanish, but it barely reaches 1.21\%, and does not appear on Table 1: un hombre-congreso, el hombre clave, etc. Spanish speakers tend to avoid this possibility, favouring other options. About Adj.P and participle clauses, there are no substantial differences between the two languages in contrast here: a mentally ill man, the man leading the investigation, un hombre inmensamente feliz, un bombre demasiado mayor, etc. The remaining structures are mostly combinations of two or more resources, but their frequency is relatively small.

The previous analysis has provided all the information necessary to draw the functional-semantic field of the characterization of human nouns in English and Spanish. Considering these data, we may suggest certain patterns that the translator who is working from English into Spanish can follow. If the noun is modified by an adjective or a relative clause, the most common options in English, the Spanish translator should consider relative clauses as the most plausible solution, and de-phrases and adjectives as additional options. If the noun is premodified by another noun with an adjectival function, the translator should reject the possibility of a formal equivalent in Spanish, since this resource presents a very low frequency of occurrence. He should rather try to make use of dephrases or single adjectives, which have a similar frequency of occurrence and function. When the English noun is characterized by an Adj.P or a participle clause, this structure is easily transferred into Spanish with a similar construction, 
since both resources present a similar frequency in both languages. The most peripheral resources in English, of-phrases and the combination of two premodifying adjectives, present similar frequency percentages to the two most peripheral resources in Spanish: adjective (or Adj.P.) plus relative clause, and adjective (or Adj.P.) plus de-phrase. Nevertheless, it seems plausible that the infrequent occurrences of of-phrases will often be translated by the very frequent formal equivalent in Spanish: de-phrase.

\subsection{CONCRETE NOUNS}

The analysis of 500 concordances corresponding to the nouns house and casa showed that there is a considerable difference in the two languages with respect to the general characterization of these nouns. Slightly over $50 \%$ of the occurrences of bouse are modified, whereas this percentage is relatively smaller in Spanish, 34.2\%. In our opinion, this fact is due to the high frequency of use on the part of native Spanish speakers of fixed expressions of the type: estar en casa, quedarse en casa, ir a casa, etc., where it is not syntactically acceptable to add any qualifying element. In all these cases, casa covers the semantic area corresponding to the noun home in English, and this could be the explanation for the lower level of characterization of the Spanish noun in this case. However, this represents no major problem here, since our aim is the description of the most frequent modifying resources in English and Spanish when the head noun is an inanimate count object. Table 2 shows the six most frequent characterizing resources found surrounding the nouns bouse and casa in our sample corpora.

\begin{tabular}{|c|c|c|c|}
\hline \multicolumn{2}{|l|}{ ENGLISH } & \multicolumn{2}{|l|}{ SPANISH } \\
\hline Adjective + bouse & $22.77 \%$ & casa + de-phrase & $43.85 \%$ \\
\hline Noun + bouse & $19.30 \%$ & cas $a+$ adjective & $10.52 \%$ \\
\hline bouse + of-phrase & $16.98 \%$ & cas $a+$ Relative clause & $9.35 \%$ \\
\hline bouse + Relative clause & $4.24 \%$ & casa + noun & $5.84 \%$ \\
\hline bouse + PP headed by in & $4.24 \%$ & casa + PP headed by en & $4.09 \%$ \\
\hline Adjective + noun + bouse & $4.24 \%$ & cas $a+$ adjective + de-phrase & $4.09 \%$ \\
\hline Noun + noun + bouse & $3.08 \%$ & cas $a+d e$-phrase + relative clause & $3.5 \%$ \\
\hline TOTAL & $74.85 \%$ & TOTAL & $81.24 \%$ \\
\hline
\end{tabular}

Table 2. Characterizing resources for house and casa. 
Again the difference with respect to the position of the modifiers is evident. But the most interesting result refers to the distribution of the frequency percentages for the different resources. De-phrases are used in almost half of the cases in Spanish, while the first three resources share approximately the same frequency in English. This difference in typicality of usage will have an important influence in the suggested translation equivalents.

Again the single adjective appears to have a much higher frequency of use in English than in Spanish: the spacious house, a terraced house, la casa imperial, una casa estupenda, etc. The noun compounding resource is very common in English here too: council house, auction bouse, etc., whereas the Spanish formal equivalent occurs in $5.84 \%$ of cases (la casa matriz, la casa Mercedes, etc.). The examples show that this unusually high frequency in Spanish is due to the use of commercial brand names after the head noun casa. Of-phrases show a relatively high frequency of use in English when compared to the modification of human nouns, and this is due to the number of occasions where political chambers are mentioned, mainly House of Commons and House of Lords. Other examples found are The House of Spirits, House of Angels, The House of Love, etc. It is important to highlight here the relatively small frequency of relative clauses when modifying inanimate count nouns, when compared to the modification of human nouns: another house somebody gave us, the bouse they bought, la casa que tiene en Obio, la casa que tú no me has podido dar, etc.

Postmodification by means of PPs headed by the prepositions in and en, in English and Spanish respectively, show a very similar frequency of occurrence of around 4\%. This coincidence is due, in our opinion, to the semantic nature of the head nouns. Houses are concrete entities, and they are also relatively big and cannot be moved around easily. In other words, houses are usually set in one specific place, and so the use of these PPs is clearly locative: her house in London, bis house in St. Louis, una casa en Noruega, una casa en medio del bosque, etc. The premodification by means of an adjective and a noun in English occurs in $4.24 \%$ of the cases: a converted coach house, a Scottish guest house, etc. Nouns and adjectives are the most common resources individually too, and the lexicalization of certain noun compounds (guest house) leads to the fact that when these compounds are to be modified, the most common characterizing resource used is still the single adjective. In Spanish $4.09 \%$ of the cases correspond to the combination of an adjective and a de-phrase, since those two are the most frequent single resources: la casa común de la izquierda, la casa natal de Juan Ramón, etc. The fixed order is determined by the length of the resources: PPs are longer structures than singleword adjectives and thus go after them. The premodification of bouse by means of 
two nouns has a frequency of $3.08 \%$, and in these cases, the noun that goes immediately before the head forms a lexicalised unit with it, while the first noun modifies the whole: a specialist (orchid house), the Carrybridge (guest house), etc. Another combination in Spanish is the one formed by de-phrases plus relative clauses (3.5\%). These are two common resources independently and again relative clauses go after the de-phrases because of their greater length and weight in the sentence structure.

The conclusions that may be drawn here refer to the most common characterizing resources in both languages independently. Thus, we are in a position to suggest the most commonly used constructions in Spanish when modifying the same type of noun. If we find in English a single adjective, a premodifying noun, or a postmodifying of-phrase, which represent the three most common constructions, any of these resources may be translated into Spanish by means of straight de-phrases, which represent almost half of the total occurrences. Nonetheless, there is also the choice of a single postmodifying adjective or a relative clause, as secondary options. In general, we can say that a relative clause in English may correspond to a parallel relative clause in Spanish. The data suggest that some of the cases of premodifying nouns in English may lead to parallel constructions in Spanish, since this type of resource is becoming more and more common in Spanish due to the influence of English. However, taking into account the percentages shown above, the most likely options for noun plus noun constructions in English are de-phrases or single adjectives in Spanish. The similar frequencies of PPs headed by in and en show that this structure may easily be translated by its formal equivalent in the other language. The most common combinations in English are adjective plus noun plus bouse and noun plus noun plus bouse, and the translator can consider as translational options the most frequent combinations in Spanish, casa plus adjective plus de-phrase or casa plus de-phrase plus relative clause. The frequency of use of these structures is very similar too.

\subsection{AbStRaCt NOUNS}

The analysis of 500 concordances of time and tiempo revealed that these two abstract nouns show a very low frequency of characterization. In my opinion, this is due to the semantics of abstract nouns, since they refer to invisible entities difficult to characterize qualitatively. The percentage of characterization is of $35.6 \%$ in English and 18.2\% in Spanish. This difference is not easy to explain, but it may be related to polysemy. When the Spanish noun tiempo was used meaning weather, and not time, the concordances usually present characterization: buen tiempo, mal tiempo, tiempo soleado, tiempo desapacible, etc. Native speakers of 
Spanish may have internalised that tiempo is mainly characterized when it means weather, and not when it has an abstract referent, meaning time.

Table 3 shows the six most common modifying resources for the nouns time and tiempo, which amount to over $90 \%$ of the total of modifying resources.

\begin{tabular}{|lr|lr|}
\hline \multicolumn{2}{|c|}{ ENGLISH } & \multicolumn{2}{c|}{ SPANISH } \\
\hline Adjective + time & $51.68 \%$ & tiempo + adjective & $31.86 \%$ \\
\hline time + Relative clause & $15.16 \%$ & tiempo + de-phrase & $27.47 \%$ \\
\hline Noun + time & $12.92 \%$ & tiempo + Relative clause & $23.07 \%$ \\
\hline time + of-phrase & $7.86 \%$ & tiempo + time adverb & $3.29 \%$ \\
\hline time + time adverb & $2.80 \%$ & tiempo + PP headed by para & $2.19 \%$ \\
\hline time + PP headed by in & $2.24 \%$ & tiempo + apposition & $2.19 \%$ \\
\hline TOTAL & $\mathbf{9 2 . 6 6} \%$ & TOTAL & $\mathbf{9 0 . 0 7 \%}$ \\
\hline
\end{tabular}

Table 3. Characterizing resources for time and tiempo.

Postmodification is again dominant in Spanish, whereas the first and third most common resources in English are premodifiers. Only the first three constructions are representative enough to be taken into account at all, since the remaining resources occur in less than $10 \%$ of the cases. Single adjectives are the most common resources in both languages, although their frequency in English (full time, hard time, useful time, borrowed time, etc.) is much higher than in Spanish (tiempo perdido, tiempo presente, tiempo libre, tiempo parcial, etc.). The remaining English resources present relatively low percentages, while the distribution is more homogeneous in Spanish, with the three most common resources sharing similar frequencies. Relative clauses appear in $15.16 \%$ of the cases in English: the time she has lost in ..., etc. In Spanish, relative clauses occupy the third place, $23.07 \%$ of the total: el tiempo que sea necesario, etc. Premodifying nouns reach $12.92 \%$ in English (war time, break time, screen time, etc.), while this same structure appears in Spanish only once in the 500 concordances analysed, and therefore does not appear in Table 3: un tiempo record.

Postmodification by means of of-phrases occurs in $7.86 \%$ of the occasions in English (the time of his death, at the time of booking, etc.), and the formally equivalent structure, de-phrase, shows $27.47 \%$ in Spanish (tiempo de retórica, tiempo de excusas, etc.) where it is the second most common construction. In very few examples the noun time appears followed by a time adverb in English (time 
ago, time before), and in Spanish (tiempo atrás, tiempo después). This fact is related to the semantic content of the head nouns.

The comparison of these resources and their frequency percentages has led to a number of conclusions concerning the most appropriate choices for the translator when dealing with abstract nouns in English and Spanish. The most central resource employed in English is the single adjective, used in over half of the occurrences. These instances will correspond to any of the three most central resources in Spanish, adjectives, de-phrases or relative clauses. As far as relative clauses are concerned, the figures show that they are common resources in both languages, and we may infer that many of these cases in English will automatically be translated by relative clauses in Spanish too. It is reasonable to consider that most of the noun plus noun structures in English be translated by means of dephrases or single adjectives in Spanish. Considering the percentages in Table 3, de-phrases might be used to cover several different constructions in English: premodifying adjectives, premodifying nouns, and of-phrases, mainly. Therefore, there is no difference between the two languages in the use of time adverbs to modify the head nouns: time before, tiempo atrás. The remaining resources present a very low frequency percentage and are not representative of the characterization of abstract nouns in either English or Spanish.

\section{CONCLUSIONS}

This paper is a contrastive analysis of the immediate syntactic environment of three pairs of nouns in English and Spanish that represent three groups: human nouns (man-hombre), inanimate count nouns (bouse-casa), and abstract nouns (time-tiempo). The contrast provided interesting data concerning the functional-semantic equivalents of the most common characterizing resources in English and Spanish, which should be of great importance and usefulness for translation purposes.

The study shows that the linguistic units and combinations that native speakers of English and Spanish employ in order to characterise nouns are not very different from a formal perspective. A similar range of noun-modifying constructions is used with a different distribution. The different distribution of formally similar resources is, in my opinion, the main reason for the translation problems in this semantic area. In spite of the wide range of different grammatical constructions available, very few formal resources account for a very high percentage of the total of noun-modifying structures. So, the five or six most common resources account for between $70 \%$ and $90 \%$ of the total of modifying forms. 
The results confirm the typological difference existing between English and Spanish in what refers to the position of adjectives and other modifying resources. Postmodification is clearly the dominant and unmarked option in Spanish for all three types of nouns, with very low premodification percentages. On the other hand, premodification is the most common and unmarked position in English, in all three cases, although postmodification occurs in the case of longer resources, such as PPs or relative clauses, that require postposition.

Adjectives, which may have been considered initially as universal noun modifiers, are less so than expected. The study shows that native speakers of English use adjectives more than native speakers of Spanish. In Bondarko's terms, adjectives are the most central resources in all three functional-semantic fields in English, while they are central in only one of the Spanish fields for nominal characterization. Relative clauses, on the other hand, are very common only in the case of human nouns, while they show much lower frequency percentages in the characterization of inanimate count nouns and abstract nouns. This pattern is found in both languages, English and Spanish. Relative clauses seem thus to be especially designed to serve their purpose with respect to human nouns.

Nouns modifying nouns in English and de-phrases in Spanish are common modifying resources, after adjectives and relative clauses. These two opposed ways of characterizing illustrate the general difference in the description of the real world in two typologically dissimilar languages. Premodifying nouns are the second most frequent resource in two of the functional-semantic fields, and the third in the other field, thus showing a very high frequency of occurrence in all types of nouns. De-phrases are the central resource in the functional-semantic field representing inanimate count nouns and the second most frequent one in the other two fields.

The division of nouns into three subgroups has revealed interesting data related to the type of characterizing structures that appear most frequently next to each type of noun. Important differences have been found between the way the three subgroups are modified. Native speakers of English and of Spanish seem to present a clear preference for modifying nouns with a human referent. The levels of characterization are somewhat lower in the case of inanimate count nouns, and extremely low in the case of abstract nouns. This is due to the lexical content of the noun type in particular. Moreover, the higher the levels of characterization, the greater the variety of different modifying structures. In what refers to the chains of modifying resources, there are some combinations that are recurrent. This is due to the fact that those resources that are most commonly used as single modifiers are also very frequently used in combinations with other common 
resources. The most common combinations are those containing the first and second most frequent resources individually.

The notion of functional-semantic fields has proved very useful to explain the relationship between a semantic content and the different grammatical realisations that may represent that meaning in two languages. In this paper we have drawn the functional-semantic fields of characterization, and we have suggested possible translational equivalents in Spanish for certain constructions in English with the same frequency of use among native speakers.

\section{REFERENCES}

Biber, D., S. Johansson, G. Leech, S. Conrad, and E. Finegan. 1999: Longman Grammar of Spoken and Written English. London: Longman.

Bondarko, A. V. 1991 (1984). Functional Grammar. A Field Approach. Amsterdam/Philadelphia: John Benjamins. Translator: I. S. Chulaki.

Darbelnet, J. 1969. Pensée et structure. New York: Charles Scribner's Sons.

Jürgens, F. 1999. Auf dem Weg zu einer pragmatischen Syntax. Tübingen: Max Niemeyer.

Pottier, B. 1992. Théorie et Analyse en Linguistique. Paris: Hachette Supérieur.

Sommerfeldt, K. E., and G. Starke. 1984. Grammatisch-semantische Felder der deutschen Sprache der Gegenwart. Leipzig: Enzyklopädie.

Tesnière, L. 1959. Éléments de syntaxe structurale. Paris: C. Klincksieck.

Toury, G. 1995. Descriptive Translation Studies and Beyond. Amsterdam/ Philadelphia: John Benjamins.

Vázquez Ayora, G. 1977. Introducción a la Traductología. Curso Básico de Traducción. Washington, D.C.: Georgetown University Press.

Vinay, J. P., and J. Darbelnet. 1958. Stylistique comparée du français et de l'anglais. Paris: Didier.

\section{COMPUTERISED CORPORA}

- Cobuild/Bank of English: http://titania.cobuild.collins.co.uk/boe_info.html.

- CREA: http://www.rae.es/NIVEL2/recursos.htm. 